\title{
PRODUÇÃO DE ÁCIDO y-POLIGLUTÂMICO POR Bacillus velezensis NRRL B-23189 UTILIZANDO GLICEROL DO BIODIESEL COMO FONTE DE CARBONO SEM A UTILIZAÇÃO DE ÁCIDO GLUTÂMICO COMO SUBSTRATO
}

\author{
L. P. MORAES ${ }^{1}$ e R. M. ALEGRE ${ }^{1}$ \\ ${ }^{1}$ Universidade Estadual de Campinas, Departamento de Engenharia de Alimentos \\ E-mail para contato: luanapdmoraes@yahoo.com.br
}

\begin{abstract}
RESUMO - O ácido y-poliglutâmico, y-PGA, é um biopolímero biodegrável, hidrossolúvel, aniônico e atóxico, composto por unidades de D- e L- ácido glutâmico e possui aplicações nas áreas médica, química e de alimentos. Este trabalho teve como objetivo estudar a produção de $\mathrm{\gamma}$-PGA por fermentação utilizando glicerol subproduto de biodiesel como fonte de carbono. O micro-organismo utilizado foi o Bacillus velezensis NRRL B-23189 e a produção de y-PGA ocorreu sem adição de ácido glutâmico ao meio de cultura. Foram estudadas diferentes concentrações de glicerol, ácido cítrico e sulfato de amônio. A avaliação das condições de cultivo foi feita com agitação de $200 \mathrm{rpm}$, temperatura de $27^{\circ} \mathrm{C}$, pH inicial de 6,5 (ajustado com NaOH 2N/HCl 2N) durante $72 \mathrm{~h}$ mediante delineamento composto central rotacional (DCCR). Para a avaliação da produção de $\mathrm{\gamma}$-PGA foi utilizada uma metodologia de quantificação via espectrofotometria a $400 \mathrm{~nm}$. A máxima produção de y-PGA em meio contendo $100 \mathrm{~g} / \mathrm{L}$ de glicerol foi de $4,17 \mathrm{~g} / \mathrm{L}$.
\end{abstract}

\section{INTRODUÇÃO}

O ácido gama-poliglutâmico ( $\mathrm{\gamma}$-PGA) é um biopolímero aniônico, biodegradável, solúvel em água (Moraes et al., 2013; Yong et al., 2011; Bajaj e Singhal, 2011; Shi et al., 2007; Shi et al., 2006 a, b; Richard e Margaritis, 2003; Goto e Kunioka, 1992). É composto das formas D- e L- do ácido glutâmico unidas pela ligação amida entre os grupos $\alpha$-amino e - $^{-c a r b o x i ́ l i c o ~(Z h a n g ~ e t ~ a l ., ~ 2011 ; ~ S h i ~}$ et al., 2007; Shi et al., 2006 a, b; Ashiuchi e Misono, 2002; Shih e Van, 2001; Kunioka, 1997; Chibnall et al., 1958).

Foi descoberto por Ivánovics e colaboradores em 1937 como cápsula de Bacillus anthracis (Goto e Kunioka, 1992). Posteriormente foi identificado como produto da fermentação de outros micro-organismos, como Bacillus subtilis ZJU-7 (Huang et al., 2011), Bacillus subtilis IFO 3335 (Goto e Kunioka, 1992), Bacillus subtilis 3-10 (Yao et al., 2012), Bacillus licheniformes, Bacillus megaterium, Bacillus amyloliquefaciens (Yong et al., 2011; Kambourova et al., 2001; Thorne e Leonard, 1958; Bovarnick, 1942). Após Bovarnick (1942) mostrar que y-PGA é acumulado em meio de cultura de Bacillus subtilis como produto de sua fermentação, muitos pesquisas foram realizadas 


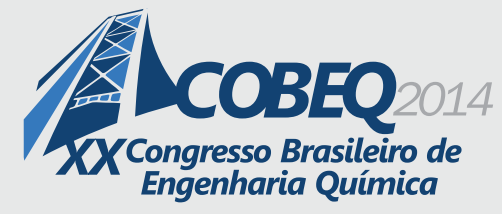

(Kunioka, 1997).

y-PGA é excretado através da parede celular, formando cápsula durante o crescimento (Do et al., 2001), e também no meio de cultura (Do et al., 2001; Kunioka e Goto, 1994). A biossíntese utilizando bactéria acontece em duas etapas. Primeiro a síntese do L- e D- ácido glutâmico e depois a união destes para formar o y-PGA (Bajaj e Singhal, 2011; Bajaj e Singhal, 2009).

¡-PGA é atóxico para o homem e ambiente (Yong et al., 2011; Bajaj e Singhal, 2011; Richard e Margaritis, 2003; Yoon et al., 2000; Shih e Van, 2001), podendo ser utilizado como espessante, umectante, em industrias de alimentos, cosmético, medicina (Chung et al., 2013; Pereira et al., 2012; Jiang et al., 2011; Hoppensack et al., 2003; Kunioka, 1997; Goto e Kunioka, 1992), farmacêutica (Shi et al., 2007), tratamento de efluentes como agente floculante (Bhunia et al., 2012). O y-PGA e seus derivados podem ser aplicados como substitutos de hidrogéis e polímeros termoplásticos. Este fato ocorre por causa de sua alta solubilidade em água e biodegrabilidade (Choi e Kunioka, 1995).

O processo fermentativo para produção do $\mathrm{\gamma}$-PGA utilizando bactérias exige diferentes requerimentos nutricionais (Kunioka, 1997; Goto e Kunioka, 1992). Alguns micro-organismos requerem diferentes fontes de carbono e nitrogênio. Algumas bactérias exigem a presença do ácido glutâmico para o crescimento (Kunioka, 1997). Há ainda as que exigem a presença de biotina para a produção do z-PGA e algumas vitaminas (Goto e Kunioka, 1992). Kunioka e Goto (1994) observaram que aparentemente o ácido glutâmico não era assimilado quando adicionado no meio e sugeriram que as unidades de ácido glutâmico utilizadas para a produção do y-PGA eram provenientes do ácido cítrico e do sulfato de amônio.

Este trabalho relata o efeito do uso de glicerol, ácido cítrico e sulfato de amônio em diferentes concentrações em meio fermentativo sem ácido glutâmico utilizando Bacillus velezensis NRRL B 23189 para a produção do -PGA.

\section{MATERIAL E MÉTODOS}

\subsection{Micro-organismo}

O micro-organismo utilizado neste trabalho para a síntese de y-PGA foi Bacillus velezensis NRRL B - 23189, fornecido pela Agricultural Research Service Culture Collection (também conhecidos como NRRL).

\subsection{Meio de Manutenção}

O meio utilizado para crescimento e manutenção do micro-organismo foi o meio de cultura BHI (brain heart infusion), utilizado conforme instruções do fabricante, junto com ágar bacteriológico, $20 \mathrm{~g} / \mathrm{L}$, ambos da marca OXOID. A mistura foi aquecida até homogeneização da solução e depois adicionado em tubos de vidro fechados e autoclavados por 15 min a $121{ }^{\circ} \mathrm{C}$.

Depois de inoculado e cultivado a $30{ }^{\circ} \mathrm{C}$ por $48 \mathrm{~h}$ o micro-organismo foi mantido a $4{ }^{\circ} \mathrm{C}$. 


\subsection{Preparo do Inóculo}

Um frasco Erlenmeyer de $250 \mathrm{~mL}$ contendo $50 \mathrm{~mL}$ de meio BHI estéril foi inoculado com alça a partir de cultura em meio semissólido. Após incubação a $30{ }^{\circ} \mathrm{C}$ por $12 \mathrm{~h}$ e agitação a 200 rpm em "shaker" (TECNAL, mod. TE 421), o conteúdo deste frasco foi utilizado como inóculo, ou seja, $5 \mathrm{~mL}$ do meio fermentado foram utilizados para inocular os frascos Erlenmeyers de 250 $\mathrm{mL}$ contendo $45 \mathrm{~mL}$ de meio de cultura (Tabela 1) e com pH inicial 6,5. Os frascos Erlenmeyers foram incubados em "shaker" com agitação de $200 \mathrm{rpm}, 72 \mathrm{~h}$ e temperatura de $27^{\circ} \mathrm{C}$.

\subsection{Inoculação e Fermentação}

Para a realização do processo fermentativo foi utilizado o método batelada.

Utilizou-se como o meio reportado por Bajaj et al. (2008) com algumas modificações (Tabela 1).

Tabela 1 - Meio proposto por Bajaj et al. (2008) com algumas modificações

\begin{tabular}{lc}
\hline \multicolumn{1}{c}{ Composição } & Quantidade $(\mathrm{g} / \mathrm{L})$ \\
\hline Glicerol & Variada \\
Ácido cítrico & Variada \\
L-ácido glutâmico & Ausente \\
Sulfato de amônio & Variada \\
$\mathrm{K}_{2} \mathrm{HPO}_{4}$ & 1 \\
$\mathrm{MgSO}_{4} \cdot 7 \mathrm{H}_{2} \mathrm{O}$ & 0,5 \\
$\mathrm{CaCl}_{2} \cdot 2 \mathrm{H}_{2} \mathrm{O}$ & 0,2 \\
$\mathrm{MnSO}_{4} \cdot 7 \mathrm{H}_{2} \mathrm{O}$ & 0,05 \\
\hline $\mathrm{pH}$ inicial $=6,5$. & \\
\hline
\end{tabular}

$\mathrm{O}$ pH inicial do meio foi ajustado para 6,5 usando $\mathrm{NaOH} 6 \mathrm{~N}$ e/ou $\mathrm{HCl} 2 \mathrm{~N}$. Os meios foram esterilizados em autoclave por $15 \mathrm{~min}$ a $121^{\circ} \mathrm{C}$.

A fermentação ocorreu em frascos Erlenmeyers com capacidade para $250 \mathrm{~mL}$ contendo 45 $\mathrm{mL}$ do meio de cultura com composição descrita conforme Tabela 1, previamente esterilizados a $121{ }^{\circ} \mathrm{C}$ por $15 \mathrm{~min}$. Os frascos foram inoculados com $10 \%$ de inóculo conforme o item preparo do inóculo e incubados por $72 \mathrm{~h}$, agitação de $200 \mathrm{rpm}$ e temperatura de $27^{\circ} \mathrm{C}$.

Todas as fermentações foram realizadas em duplicata. As amostras foram retiradas ao final das $72 \mathrm{~h}$ de fermentação para análise de quantificação de -PGA. 


\subsection{Planejamento Experimental}

Usou-se planejamento fatorial $2^{3}$ com seis pontos axiais e quatro pontos centrais, totalizando 18 ensaios conforme a Tabela 2, de resultados e discussão, que apresenta os valores reais e codificados das variáveis: glicerol (x1), ácido cítrico (x2) e sulfato de amônio (x3) para os 18 tratamentos. Os resultados foram analisados pela metodologia de superfície de resposta, utilizando-se como ferramenta o software Statistica 5.0. O polinômio empregado para ajuste do modelo foi o descrito pela Equação 1:

$$
Y=b_{o}+\sum_{i=1}^{4} b_{i} x_{i}+\sum_{i=1}^{4} b_{i i} x_{i}^{2} \sum \sum_{i \neq j=I}^{4} b_{i j} x_{i} x_{j}
$$

Em que: $b_{o}=$ constante, $b_{i}=$ coeficiente linear, $b_{i i}=$ coeficiente quadrático, $b_{i j}=$ coeficiente da interação, $x_{i}$ e $x_{j}=$ níveis das variáveis independentes e $Y=$ variável dependente.

\subsection{Análise dos Resultados}

Centrifugação do caldo de cultura: Após 72 h de fermentação, centrifugou-se o caldo de cultura por 20 min a $2300 \mathrm{~g}$ para a separação das células, utilizando centrífuga Excelsa Baby II (FANEM, mod. 206-R).

Determinação do $\gamma$-PGA: Coletou-se uma alíquota do sobrenadante proveniente da centrifugação do caldo de cultura após $72 \mathrm{~h}$ de fermentação para a determinação do $\gamma$-PGA, seguindo a metodologia descrita por Silva (2010).

\section{RESULTADOS E DISCUSSÃO}

Para o estudo do efeito da concentração de glicerol, ácido cítrico e sulfato de amônio no processo fermentativo utilizando Bacillus velezensis NRRL B - 23189 para a produção de $\gamma^{-}$ PGA realizou-se um DCCR $2^{3}$. As condições para o processo fermentativo foram temperatura de $27^{\circ} \mathrm{C}, \mathrm{pH}$ inicial 6,5 e agitação de $200 \mathrm{rpm}$ em "shaker".

A Tabela 2 apresenta os resultados da produção do y-PGA. Segundo Richard e Margaritis (2003) e Kunioka e Goto (1994), a adição de glicerol ou outra fonte de carbono no meio fermentativo contribuem para biossíntese do y-PGA. A Tabela 2 mostra que a adição de glicerol como fonte de carbono e do sulfato de amônio não indicam aumento na biossíntese do f-PGA. A partir da concentração de $100 \mathrm{~g} / \mathrm{L}$ para o glicerol e $8 \mathrm{~g} / \mathrm{L}$ para o sulfato de amônio ocorreu decréscimo no processo produtivo do $\mathrm{\gamma}$-PGA. 
Tabela 2 - Produção do y-PGA para os tratamentos analisados

\begin{tabular}{|c|c|c|c|c|}
\hline \multirow{2}{*}{ Ensaios } & \multicolumn{3}{|c|}{ Valores Codificados (Valores Reais - g/L) } & \multirow[t]{2}{*}{$\gamma$-PGA $(g / L)$} \\
\hline & $\mathrm{x} 1$ & $\mathrm{x} 2$ & $\mathrm{x} 3$ & \\
\hline 1 & $-1(80)$ & $-1(15)$ & $-1(4)$ & 2,709 \\
\hline 2 & $+1(120)$ & $-1(15)$ & $-1(4)$ & 4,311 \\
\hline 3 & $-1(80)$ & $+1(25)$ & $-1(4)$ & 3,727 \\
\hline 4 & $+1(120)$ & $+1(25)$ & $-1(4)$ & 2,877 \\
\hline 5 & $-1(80)$ & $-1(15)$ & $+1(12)$ & 3,116 \\
\hline 6 & $+1(120)$ & $-1(15)$ & $+1(12)$ & 2,583 \\
\hline 7 & $-1(80)$ & $+1(25)$ & $+1(12)$ & 3,700 \\
\hline 8 & $+1(120)$ & $+1(25)$ & $+1(12)$ & 3,559 \\
\hline 9 & $-1,68(66,4)$ & $0(20)$ & $0(8)$ & 3,329 \\
\hline 10 & $+1,68(133,6)$ & $0(20)$ & $0(8)$ & 3,753 \\
\hline 11 & $0(100)$ & $-1,68(11,6)$ & $0(8)$ & 3,329 \\
\hline 12 & $0(100)$ & $+1,68(28,4)$ & $0(8)$ & 3,939 \\
\hline 13 & $0(100)$ & $0(20)$ & $-1,68(1,28)$ & 3,116 \\
\hline 14 & $0(100)$ & $0(20)$ & $+1,68(14,72)$ & 3,408 \\
\hline 15 & $0(100)$ & $0(20)$ & $0(8)$ & 4,205 \\
\hline 16 & $0(100)$ & $0(20)$ & $0(8)$ & 4,205 \\
\hline 17 & $0(100)$ & $0(20)$ & $0(8)$ & 4,046 \\
\hline 18 & $0(100)$ & $0(20)$ & $0(8)$ & 4,258 \\
\hline
\end{tabular}

A máxima produção de y-PGA foi atingida nos ensaios 15, 16, 17 e 18 que representam o ponto central, onde todas as variáveis encontram-se no nível 0 , que representa $100 \mathrm{~g} / \mathrm{L}$ de glicerol, $20 \mathrm{~g} / \mathrm{L}$ de ácido cítrico e $8 \mathrm{~g} / \mathrm{L}$ do sulfato de amônio. Pode-se também observar pela Tabela 2, que o ensaio 2 apresentou valores similares para a produção de $\gamma$-PGA. Por outro lado, a mínima biossíntese do y-PGA foi obtida em níveis com baixa concentração de glicerol ou em níveis com alta concentração de glicerol. Resultados semelhantes foram obtidos por Moraes e colaboradores (2012) utilizando melaço como fonte de carbono. 
Pelo cálculo da análise da variância (ANOVA) observa-se que o $\mathrm{F}$ calculado $(3,336)$ é maior que o F tabelado $(2,56)$, ao nível de $90 \%$ de confiança, indicando a validade do modelo proposto para produção de $\mathrm{\gamma}$-PGA (Tabela 3 ).

Tabela 3 - Análise de variância (ANOVA) para o modelo de regressão ajustado da produção de $\gamma$-PGA

\begin{tabular}{lccccc}
\hline \multicolumn{1}{c}{ FV } & SQ & GL & QM & F calculado & F tabelado $(0,05 ; 9 ; 8)$ \\
\hline Regressão & 4,590 & 9 & 0,510 & \multirow{2}{*}{3,336} & 2,56 \\
Resíduo & 1,223 & 8 & 0,153 & & \\
\hline Falta de Ajuste & 1,198 & 5 & 0,240 & \multirow{2}{*}{28,430} & F tabelado $(0,05 ; 5 ; 3)$ \\
\cline { 3 - 6 } Erro Puro & 0,0253 & 3 & 0,008 & & 5,31 \\
\hline Total & 5,814 & 17 & \multicolumn{2}{c}{ Nível de confiança $=90 \% ; \mathrm{R}^{2}=0,7562$} \\
\hline
\end{tabular}

A equação ajustada pelo modelo de regressão (Tabela 4) para a produção do y-PGA apresentou coeficiente de determinação de 0,7562 , ou seja, $75,62 \%$ dos pontos obtidos experimentalmente são explicados pelo modelo (Equação 2).

$$
Y=4,184+0,058 x 1-0,250 x 1^{2}+0,159 x 2-0,217 x 2^{2}-0,013 x 3-0,349 x 3^{2}-0,285 x 1 . x 2-
$$

$0,178 \times 1 . x 3-0,247 x 2 . x 3$

Tabela 4 - Coeficientes estimados pelo modelo de regressão ajustados da produção do $\gamma$-PGA

\begin{tabular}{lcc}
\hline Variáveis Independentes & $\begin{array}{c}\text { Coeficientes } \\
\text { Regressão }\end{array}$ & de \\
& 4,184 & 0,000000 \\
\hline Interceptação & 0,058 & 0,599007 \\
Glicerol (L) & $-0,250$ & 0,052545 \\
Glicerol (Q) & 0,159 & 0,171592 \\
Ácido Cítrico (L) & $-0,217$ & 0,083677 \\
Ácido Cítrico (Q) & $-0,013$ & 0,906639 \\
Sulfato de Amônio (L) * & $-0,349$ & 0,013167 \\
Sulfato de Amônio (Q) * & $-0,258$ & 0,099532 \\
Glicerol X Ácido Cítrico* & $-0,178$ & 0,233302 \\
Glicerol X Sulfato de Amônio* & 0,247 & 0,111810 \\
Ácido Cítrico X Sulfato de Amônio* & & \\
\hline
\end{tabular}

O efeito do componente que mais influenciou a produção do y-PGA foi o ácido cítrico $(\mathrm{p}<$ 0,1). Em geral, todos os efeitos influenciaram pouco na produção do y-PGA.

As Figuras 1, 2 e 3 mostram as superfícies de resposta para a resposta produção do y-PGA. $\mathrm{Na}$ construção das superfícies as variáveis não explicitadas estão fixadas no ponto central (nível $0)$. 


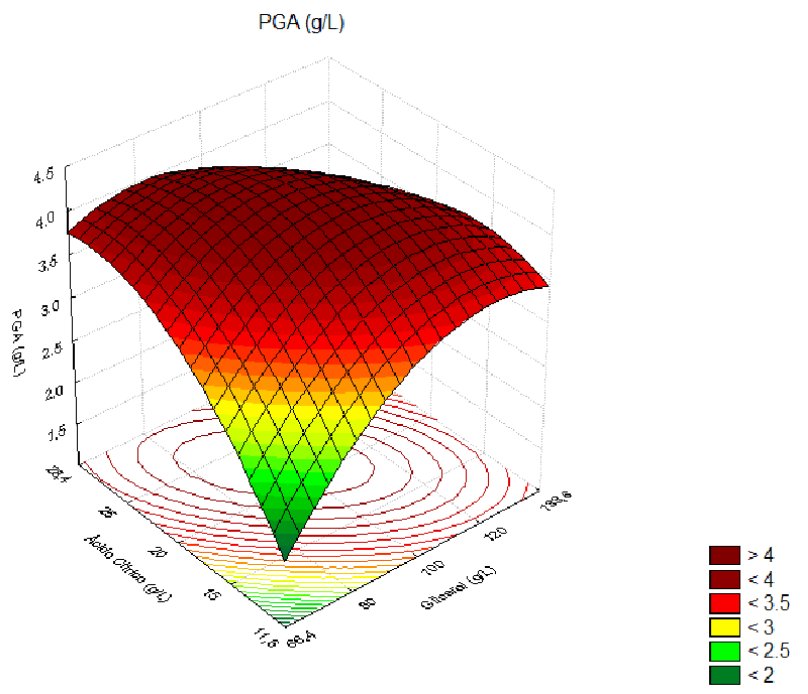

Figura 1 - Superfície de resposta gerada pela resposta concentração de y-PGA, em função da concentração de sulfato de amônio no ponto central, em meio fermentado contendo glicerol como substrato, produzido por Bacillus velezensis NRRL B-23189, 72 h, agitação de 200 rpm.

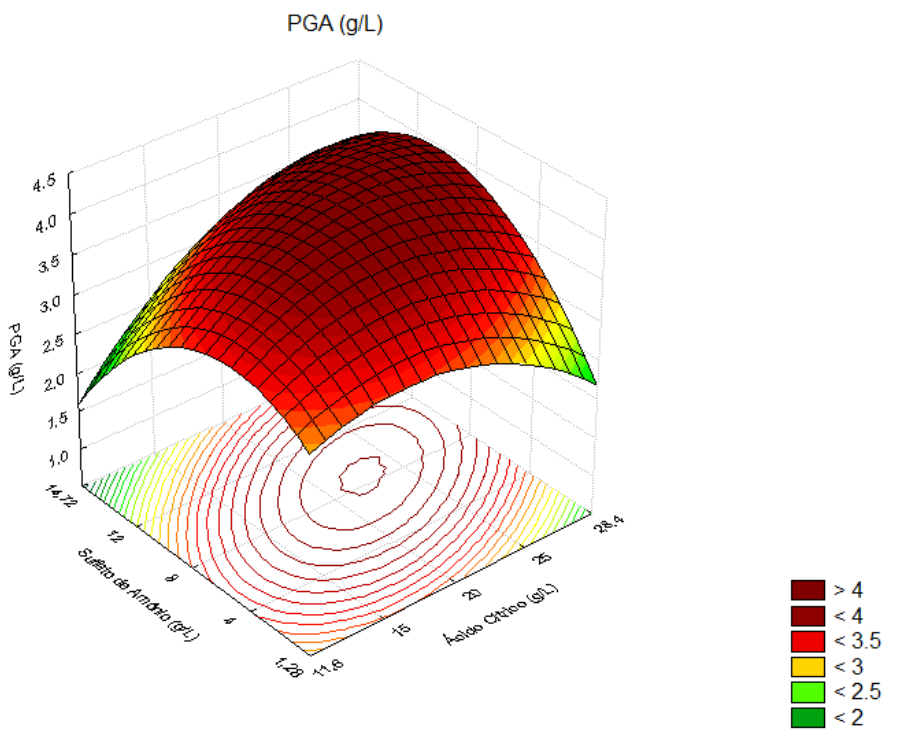

Figura 2 - Superfície de resposta para a resposta y-PGA, em função da concentração de glicerol no ponto central, em meio fermentado contendo glicerol como substrato, produzido por Bacillus velezensis NRRL B-23189, 72 h, agitação de 200 rpm. 


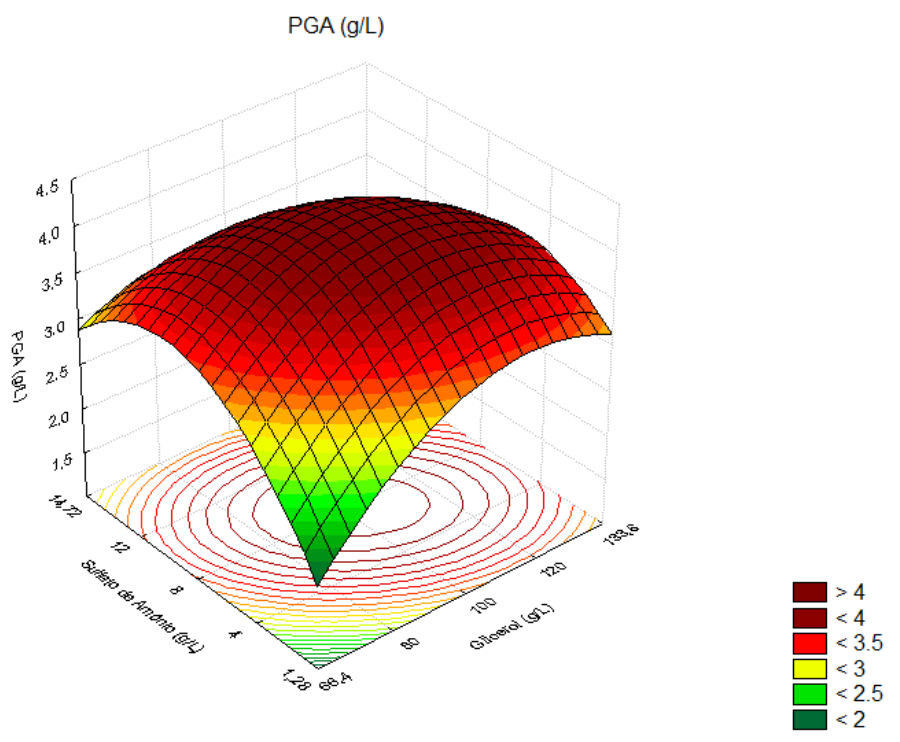

Figura 3 - Superfície de resposta para a resposta y-PGA, em função da concentração de ácido cítrico no ponto central, em meio fermentado contendo glicerol como substrato, produzido por Bacillus velezensis NRRL B-23189, 72 h, agitação de 200 rpm.

Observando os gráficos pode-se afirmar que a maior produção de y-PGA ocorreu próximo ao ponto central com $100 \mathrm{~g} / \mathrm{L}$ de glicerol, $8 \mathrm{~g} / \mathrm{L}$ do sulfato de amônio e entre 20 e $25 \mathrm{~g} / \mathrm{L}$ do ácido cítrico.

Para obtenção da melhor resposta fez-se nova fermentação em duplicata, nas mesmas condições, dos ensaios 2 e 15 que proporcionaram melhores resultados com relação à produção do -PGA e aplicou-se o teste de Tukey a 5\% de probabilidade para observar se existia diferença entre as médias. Os resultados de quantificação do y-PGA estão descritos na Tabela 5.

Tabela 5 - Produção do y-PGA utilizando Bacillus velezensis NRRL B - 23189, temperatura de $27^{\circ} \mathrm{C}$, após $72 \mathrm{~h}, \mathrm{pH}$ inicial de 6,5 e agitação de $200 \mathrm{rpm}$

\begin{tabular}{|c|c|}
\hline Ensaios & y-PGA $\left(\right.$ g.L $\left.L^{-1}\right)$ \\
\hline 3 & $4,152 \pm 0,0376^{\mathrm{a}}$ \\
\hline 15 & $4,205 \pm 0,0376^{\mathrm{a}}$ \\
\hline
\end{tabular}

As médias seguidas por uma mesma letra não diferem entre si ao nível de $5 \%$ de probabilidade pelo teste de Tukey.

\section{CONCLUSÃO}

Neste trabalho mostrou-se que ocorre produção do y-PGA sem a necessidade de adição do ácido glutâmico no meio fermentativo e que a adição da fonte de carbono e nitrogênio não 


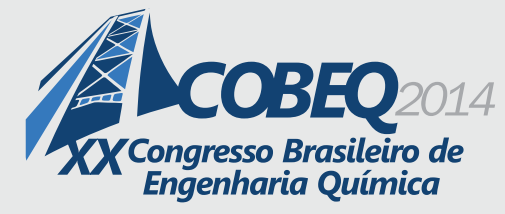

aumenta a produção de $\gamma$-PGA. A máxima produção do $\gamma$-PGA foi de aproximadamente $4 \mathrm{~g} / \mathrm{L}$ e ocorreu em 2 diferentes formulações de meio de cultura, sendo uma delas $100 \mathrm{~g} / \mathrm{L}$ de glicerol, 8 $\mathrm{g} / \mathrm{L}$ do sulfato de amônio e $20 \mathrm{~g} / \mathrm{L}$ de ácido cítrico produzindo 4,17 g/L do y-PGA.

Os resultados obtidos mostraram que é possível produzir y-PGA utilizando subprodutos industriais, glicerol, como fonte de carbono pelo micro-organismos Bacillus velezensis NRRL23189 sem a necessidade da utilização do ácido glutâmico no meio fermentativo.

A adição de ácido glutâmico no meio de cultivo não é necessária e a substituição de extrato de levedura e/ou peptona por sulfato de amônio reduz o custo do meio de cultivo.

\section{REFERÊNCIAS}

ASHIUCHI, M.; MISONO, H. Biochemistry and molecular genetics of poly- $\gamma$-glutamate synthesis. Appl. Microbiol. Biotechnol., v. 59, p. 9-14, 2002.

BAJAJ, I. B.; LELE, S. S.; SINGHAL, R. S. Enhanced production of poly( $\gamma$-glutamic acid) from Bacillus licheniformis NCIM2324 in solid state fermentation. Journal of Industrial Microbiology and Biotechnology, v. 35, p. 1581-1586, 2008.

BAJAJ, I. B.; SINGHAL, R. S. Enhanced production of poly ( $\gamma$-glutamic acid) from Bacillus licheniformis NCIM 2324 by using metabolic precursors. Appl. Biochem. Biotechnol., v. 159, p. 133-141, 2009.

BAJAJ, I.; SINGHAL, R. An emerging biopolymer of commercial interest. Bioresource Technology, v. 102, p. 5551-5561, 2011.

BHUNIA, B.; MUKHOPADHY, D. G. S.; MANDAL, T.; DEY, A. Improved production, characterization and flocculation properties of poly ( $\mathrm{\gamma}$ )-glutamic acid produced from Bacillus subtilis. J Biochem Tech, v. 3, p. 389-394, 2012.

BOVARNICK, M. The formation of extracellular $d(-)$-glutamic acid polypeptide by Bacillus subtilis. J. Biol. Chem., v. 145, p. 415-424, 1942.

CHIBNALL, A. C.; RESS, M. W., RICHARDS, F. M. Structure of the polyglutamic acid from Bacillus subtilis. Bioch., v. 68, p. 129-135, 1958.

CHOI, H. J.; KUNIOKA, M. Preparation conditions and swelling equilibria of hydrogel prepared by $\mathrm{\gamma}$-irradiation from microbial poly( $\mathrm{\gamma}$-glutamic acid). Radiat. Phys. Chem., v. 46, p. 175-179, 1995. 


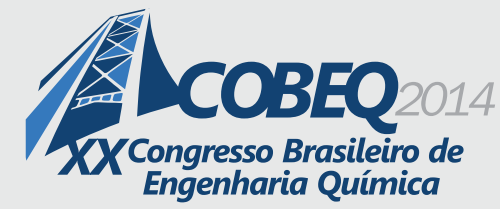

CHUNG, S.; GENTILINI, C.; CALLANAN, A.; HEDEGAARD, M.; HASSING, S.; STEVENS, M. M. Responsive poly ( $\mathrm{\gamma}$-glutamic acid) fibres for biomedical applications. Journal of Materials Chemistry B, v. 1, p. 1397-1401, 2013.

DO, J. H.; CHANG, H. N.; LEE, S. Y. Efficient recovery of $\gamma$-poly (glutamic acid) from highly viscous culture broth. Biotechnology and Bioengineering, v. 76, p. 219-223, 2001.

GOTO, A; KUNIOKA, M. Biosynthesis and hydrolysis of poly( $\gamma$-glutamic acid) from Bacillus subtilis IFO3335. Biosci. Biotech. Biochem., v. 56, p. 1031-1035, 1992.

HOPPENSACK, A.; OPPERMANN-SANIO, F. B.; STEINBÜCHEL, A. Conversion of the nitrogen content in liquid manure into biomass and polyglutamic acid by a newly isotated strain of Bacillus licheniformis. FEMS Microbiology Letters, v. 218, p. 39-45, 2003.

HUANG, J.; DU, Y.; XU, G.; ZHANG, H.; ZHU, F.; HUANG, L.; XU, ZHINAN, X. High yield and cost-effective production of poly(y-glutamic acid) with Bacillus subtilis. Eng. Life Sci., v. 11, p. 291-297, 2011.

JIANG, F.; QI, G.; JI, Z.; ZHANG, S.; LIU, J.; MA, X. CHEN, S. Expression of glr gene encoding glutamate racemase in Bacillus licheniformis WX-02 and its regulatory effects on synthesis of poly- $\gamma$-glutamic acid. Biotechnol Lett, v. 33, p. 1837-1840, 2011.

KAMBOUROVA, M.; TANGNEY, M.; PRIEST, F. G. Regulation of polyglutamic acid synthesis by glutamate in Bacillus licheniformis and Bacillus subtilis. Applied and Environmental Microbiology, v. 67, p. 1004-1007, 2001.

KUNIOKA, M. Biosynthesis and chemical reactions of poly(amino acid)s from microorgabisms. Appl. Microbiol. Biotechnol., v. 47, p. 469-475, 1997.

KUNIOKA, M; GOTO, A. Biosynthesis of poly( $\gamma$-glutamic acid) from L-glutamic acid, citric acid, and ammonium sulfate in Bacillus subtilis IFO3335. Appl. Microbiol. Biotechnol., v. 40, p. 867-872, 1994.

MORAES, L. P.; ALEGRE, R. M.; BRITO, P. N. Optimisation of poly(y-glutamic acid) production by Bacillus velezenis NRRL B - 23189 in liquid fermentation with molasses as the carbon source without addition of glutamic acid. International Review of Chemical Engineering (I.R.E.C.H.E), v. 4, p. 618-623, 2012.

MORAES, L. P.; ALEGRE, R. M.; BRITO, P. N. The existing studies on biosynthesis of poly(yglutamic acid by fermentation). Food and Public Health, v.3, p. 28-36, 2013. 


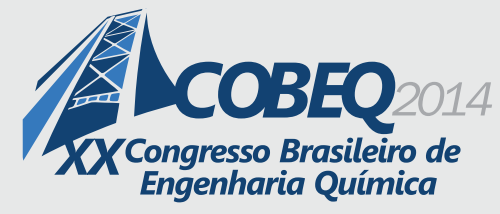

PEREIRA, C. L.; $\quad$ ANTUNES, J. C.; GONÇALVES, R. M.; FERREIRA-DA-SILVA, F.; BARBOSA, M. A. Biosynthesis of highly pure poly-y-glutamic acid for biomedical application. J Mater Sci: Mater Med, v. 23, p. 1583-1591, 2012.

RICHARD, R.; MARGARITIS, A. Optimization of cell growth and poly(glutamic acid) production in batch fermentation by Bacillus subtilis. Biotechnology Letters, v. 25, p. 465-468, 2003.

SHI, F.; XU, Z.; CEN, P. Microbial production of natural poly amino acid. Sci China Ser BChem, v. 50, p. 291-303, 2007.

SHI, F.; XU, Z.; CEN, P. Efficient production of poly- $\gamma$-glutamic acid by Bacillus subtilis ZJU-7. Applied Biochemistry and Biotechnology, v. 133, p. 271-281, 2006.

SHI, F.; XU, Z.; CEN, P. Optimization of $\gamma$-polyglutamic acid production by Bacillus subtilis ZJU-7 using a surface-response methodology. Biotechnology and Bioprocess Engineering, v. 11, p. 251-257, 2006.

SHIH, I. L.; VAN, Y. T. The production of poly-( $\gamma$-glutamic acid) from microorganisms and its various applications. Bioresource Technology, v. 79, p. 207-225, 2001.

SILVA, S. B. Produção e otimização de processo de obtenção de ácido $\gamma$-poliglutâmico através do cultivo de Bacillus subtilis BL53. Tese de doutorado, Universidade Federal do Rio Grande do Sul, Escola de Engenharia, Departamento de Engenharia Química, 2010.

THORNE, C. B.; LEONARD, C. G. Isolation of D- and L-glutamyl polypeptides from culture filtrates of Bacillus subtilis. J. Biol. Chem., v. 233, p. 1109-1112, 1958.

YAO, D.; JI, Z.; WANG, C.; QI, G.; ZHANG, L.; MA, X.; CHEN, S. Co-producing iturin A and poly-y-glutamic acid from rapessed meal under solid state fermentation by the newly isolated Bacillus subtilis strain 3-10. World J Microbiol Biotechnol, v. 28, p. 985-991, 2012.

YOON, S. H.; DO, J. H.; LEE, S. Y.; CHANG, H. N. Production of poly- $\gamma$-glutamic acid by fedbatch culture of Bacillus licheniformis. Biotechnology Letters, v. 22, p. 585-588, 2000.

ZHANG, D.; XU, Z.; XU, H.; FENG, X.; LI, S.; CAI, H.; WEI, Y.; OUYANG, P. Improvement of poly( $\mathrm{\gamma}$-glutamic acid) biosynthesis and quantitative metabolic flux analysis of a two-stage strategy for agitation speed control in the culture of Bacillus subtilis NX-2. Biotechnology and Bioprocess Engineering, v. 16, p. 1144-1151, 2011. 